\title{
Introduction: The Contributions of Australian Surgeons to World Surgery
}

\author{
John G. Hunter
}

Published online: 9 June 2009

(C) Société Internationale de Chirurgie 2009

International Surgical Week traverses the globe every other year, bringing surgeons from Africa, the Americas, Asia, Europe, the Middle East, and the great countries of Australia and New Zealand together to exchange ideas, information, and collegiality. The focus of the congress week is the art, the science, and the practice of surgery from Tiburon to Timbuktu, from Beijing to Bahrain. During my tenure as the Editor of the World Journal of Surgery, it has become apparent that the success of this congress correlates directly with the contributions of the surgical community in the host country. This year, from September 6 to 10 , the International Surgery Society-Societe Internationale de Chirurgie and its integrated and partner societies will meet in Adelaide, Australia. A number of Australian Surgical Societies will meet with us. In recognition of the many and varied contributions of Australian surgeons to world surgery, the WJS is proud to publish this symposium, guest edited by Glynn Jamieson, the Professor and Chair of Surgery from the University of Adelaide. Professor Jamieson is an internationally respected esophageal surgeon and has been an outspoken advocate of submitting our many operations to evaluation with randomized clinical trials. Under his leadership, Australian surgeons have had a great influence on the practice of esophageal surgery in all corners of the globe. I am deeply indebted to you, Glynn, for your stewardship of this symposium.
J. G. Hunter $(\square)$

Department of Surgery, School of Medicine, Oregon Health Sciences University, 3181 SW Sam Jackson Road, Portland, Oregon 97239, USA

e-mail: hunterj@ohsu.edu 